\title{
HEART DISEASE IN PREGNANCY
}

\author{
Stanley G. Clayton, M.D., M.S., F.R.C.S., F.R.C.O.G. \\ Obstetric and Gynaecological Surgeon, King's College Hospital London, S.E.5, Queen Charlotte's Hospital, London, W \\ and Chelsea Hospital for Women, London, S.W.3
}

DURING pregnancy the work done by the heart is greatly increased. While the extra effort is easily accomplished by the normal heart, the additional load may not be carried safely by a diseased heart. In recent years there has been a great reduction in the number of deaths in pregnancy, labour and the puerperium due to heart disease, yet $11.7 \%$ of maternal deaths in England and Wales are still attributed to this cause, and apart from the immediate risk, the question whether pregnancy may adversely affect the long-term maternal prognosis must also be considered.

\section{Physiological Changes During Pregnancy}

Before discussing the effect of pregnancy on the abnormal heart we may first review the changes in the circulation which occur during normal pregnancy.

The heart rate. Observations under standard conditions show that in most normal women there is a gradual increase of about ro beats per minute up to the thirty-second week, but that thereafter the rate falls to the initial level at term. Even this slight increase represents 14,000 additional beats per day. (Burwell, Strayhorn, Flickinger, Corlette, Bowerman and Kennedy, 1938; Brehm and Kindling, 1955).

The arterial pressure. In most normal women the systolic pressure remains unchanged, but the diastolic pressure falls by about $10 \mathrm{~mm}$. $\mathrm{Hg}$ to reach its lowest level at about the thirtieth week, and then rises again towards term. (Burwell and others, 1938; Adams, 1954; Brehm and Kindling, 1955).

The cardiac output. The cardiac output during pregnancy has been studied by many methods (Burwell and others, 1938; Hamilton, 1949; Werkö, 1954; Adams, 1954), and all recent observers agree that the output rises to between 30 and $50 \%$ above the non-pregnant level by about the thirtieth week. It is maintained at this level until about four weeks before term, when a striking change occurs and the output falls so that it nearly, but not quite, reaches the starting level by term.

The great rise in the cardiac output and its subsequent fall occur simultaneously with the slight rise and fall in the pulse rate and pul $\overrightarrow{8}$ pressure, but the change in the heart rate is too slight to explain the increased output, and $\overrightarrow{8}$ achieve this it is evident that the heart must expel more blood at each stroke. Since the change in the blood pressure is also slight it is obvious that the blood leaving the heart must meet og lowered peripheral resistance, and the reason for this may now be considered.

The peripheral circulation. Clinical observatiof shows that there is some dilatation of the peropheral capillaries. Pregnant women are seldom troubled by cold feet and hands, and reddening of the palms and digital capillary pulsation can of te be observed. The vasodilatation has beem attributed to œstrogens, but it is also a respense to the metabolism of the fœetus, whose heat foss must occur through the mother.

Changes in the blood flow through the visce are less easily studied but are more important. Tloe greatest change is in the uterine vessels, whose tremendous hypertrophy is obvious, but direot measurement of uterine blood flow in hum $\overrightarrow{\text { hi }}$ pregnancy is not possible. By indirect methods $3 t$ has been shown that at term there is an average flow of $500 \mathrm{ml}$. per minute (Asali, Douglas, Baird, Nicholson and Suyemoto, 1953; Metcaff, Romney, Ramsey, Reid and Burwell, r955). $\overrightarrow{\mathrm{m}}$ animals the flow reaches its maximum when abost three-fourths of pregnancy has passed, and the्gा falls again as term is approached (Newton, I93@; Barcroft, Herkel and Hill, 1933), and we may guess that the same fall occurs in human pregnanco

It is likely that the flow through the brais (McCall, 1949) and liver (Munnell and Tayloz, I947) is unaltered. The total renal blood flow probably increased (Bucht, I95 I). The pulmonary blood flow must obviously be increased if the cardiac output is increased, but there is sonqe uncertainty about the pulmonary resistance a blood volume. 'Increased vascular markinge' have often been noted on radiological examinatiog, but Werkö (1950) concluded that the pressure in the pulmonary artery was slightly reduced and that the pulmonary blood volume was not altere whereas Adams (1954) thought that the pulmonas 
blood volume was increased at the thirtieth week of pregnancy.

The reason for the increased cardiac output. The idea that the utero-placental vessels form an arterio-venous shunt has much support. In many mammals the uterine blood flow rises for about three-fourths of pregnancy and then falls in the last quarter. If such a shut-down of the hypothetical shunt also occurred towards the end of human pregnancy it would explain the late fall in cardiac output and the reversal of some of the other circulatory changes.

The increase in output is greater than is required to meet the increased total oxygen demand during pregnancy.

Respiratory function during pregnancy. The maternal oxygen consumption rises progressively during pregnancy from about 175 to $225 \mathrm{ml}$. per minute, and pulmonary ventilation is increased by about $50 \%$, chiefly by added depth of respiration rather than by increase in the respiratory rate. The increase in ventilation exceeds the increase in oxygen consumption, and there is a reduction in the alveolar carbon dioxide tension (Plass and Oberst, 1938). Slight dyspnœa, or at least heightened consciousness of breathing, is frequently noticed during late pregnancy, yet the pulmonary vital capacity is not decreased but is in fact increased by up to $12 \%$ (Cugell, Frank, Gænsler and Badger 1953; Widlund, 1945).

\section{Physiological Changes During Labour and the Puerperium}

Because of difficulties of investigation few exact studies of cardiac function during normal labour have been made. During each contraction some maternal blood is squeezed out into the general circulation, and the blood flow through the intervillous space is arrested (Woodbury, Hamilton and Torpin, 1938). The muscular efforts of labour call for as much oxygen as does severe exercise. The pulse rate tends to rise during the early phase of each contraction, although the effects of emotion, pain, hæmorrhage or analgesic drugs confuse observation. Hendricks and Quilligan (1956) concluded that the cardiac output rose by $30 \%$ with each contraction.

During the normal puerperium the pulse rate is often slow, but Adams (1954) found that the cardiac output was $13 \%$ above the non-pregnant level, and that it took two weeks to return to normal.

\section{The Diagnosis of Heart Disease During Pregnancy}

Only $40 \%$ of pregnant women with heart disease have symptoms before pregnancy (Marshall, 1949), and it is still not uncommon for the first discovery of heart disease to be made in the antenatal clinic; the importance of routine examination of the heart in pregnancy is evident. In a few cases pregnancy may reveal or intensify a diastolic murmur, so that it then becomes certain for the first time that the patient has an organic lesion. When any cardiac abnormality is suspected the doctor must be careful not to cause needless apprehension; many pregnant women referred to the cardiologist for his opinion are found to have healthy hearts, and if this proves to be the case the patient should be told this clearly.

During pregnancy it may be difficult to decide whether organic cardiac disease is present, as many of the usual signs and symptoms of disease may be mimicked, at least in part, by physiological changes. For example, dyspnœa on effort is common in normal pregnancy, although it is not found before the last four months, and dyspncea in early pregnancy is significant. Edema of the ankles occurs in many cases of normal pregnancy towards term, and it is common in cases of preeclampsia. It is most unlikely to be due to heart disease unless the disease is advanced and there is also severe dyspnœa. Persistent tachycardia of more than 100 beats per minute at rest is not seen during normal pregnancy and always requires investigation. Fainting attacks sometimes occur during normal pregnancy, and are practically never evidence of heart disease.

Signs of pulmonary or hepatic congestion are difficult to elicit during pregnancy. Although a few basal crepitations may be heard on auscultation of the lung bases towards term these will disappear if the patient takes a few deep breaths. Persistent crepitations must be taken as evidence of pulmonary congestion. Hæmoptysis is never due to normal pregnancy. Hepatic enlargement and tenderness will be obscured by the uterus near term. In normal pregnancy without heart disease a slight rise in jugular venous pressure can often be observed, as Mackenzie first noted in $192 \mathrm{I}$, so that this sign, which is usually so valuable, may be less useful in pregnancy than in non-pregnant women.

Difficulties also arise during examination of the heart. There may be changes in the heart sounds during normal pregnancy. The first sound may be split, the third sound may become evident, and the pulmonary second sound is accentuated. In addition an apical systolic murmur may appear, and occasionally a pulmonary systolic murmur (Jensen, I938), so that the difficulties of auscultation are evident, and although the expert may have little difficulty in distinguishing these sounds they often confuse the ordinary observer. However, any diastolic murmur is certain evidence of heart disease, and so are loud and harsh systolic 
murmurs (grade III or more) and any murmur accompanied by a thrill.

Other difficulties arise during radiological examination. In pregnancy the heart comes to lie more transversely to give the appearance of slight left ventricular hypertrophy, and in an oblique view the left auricle appears to be enlarged (Oram, 195I; Ungerleider and Clark, 1939). Only unequivocal cardiac enlargement is evidence of heart disease in pregnancy.

The rotation of the heart causes a shift in its electrical axis and changes in the ECG. In lead III the $\mathrm{Q}$ wave is deep and the $\mathrm{T}$ wave may be inverted (Hollander and Crawford, r943; Oram, I95I).

\section{Incidence of Heart Disease in Pregnancy}

Estimates of the incidence of heart disease in pregnancy differ because diagnostic criteria vary. Although many American authorities have reported an incidence of between $I$ and $3 \%$ (Burwell and Metcalf, I958), at Queen Charlotte's Hospital (I96I) the incidence was only $0.6 \%$ among 18,323 deliveries.

\section{Aetiology and Pathology Rheumatic Carditis}

By far the commonest disorder found during pregnancy is rheumatic valvular disease, which now accounts for between 85 and $95 \%$ of cases (Bramwell and Longson, 1938; Burwell and Metcalf, 1958; Hamilton and Thomson, I94I; Mendelson, 1955), although in future the incidence is likely to fall. About two-thirds of these patients give a history of rheumatic fever or chorea. Burwell and Metcalf classified 236 cases according to the 'predominant lesion', and found mitral stenosis in $65 \%$, mitral regurgitation in $24 \%$, aortic stenosis in $1 \%$, and aortic regurgitation in $10 \%$ of the cases.

Mitral stenosis is the commonest lesion found. It is seldom complicated by right ventricular failure or embolism during pregnancy; pulmonary œdema is the chief danger. In cases of mitral stenosis the increased output during pregnancy can only be achieved if there is increased flow through the stenosed valve, and this may require increased pressure in the atrium and pulmonary vessels. If the pulse rate rises, diastole is shortened, and then the atrial pressure must rise further to maintain the diastolic filling of the ventricle. Auricular fibrillation is not often seen, but carries a grave prognosis as it indicates myocardial damage. Bramwell and Longson (1938) and Hamilton and Thomson (194I) found the mortality in such cases to be about $30 \%$.

Mitral regurgitation is difficult to diagnose during pregnancy unless there is a loud and harsh murmur. On the whole it is a benign lesion, and dangerous pulmonary congestion only occurs when the left ventricle fails, which is uncommo in the childbearing years.

Aortic lesions carry the same risk as in the non-pregnant. Isolated aortic lesions are nof more dangerous than mitral lesions, nor does the addition of an aortic to a mitral lesion much alte the prognosis. The state of the myocardium at the time is the important factor, not the type of valvular lesion.

Acute rheumatic fever is very rare during pregnancy, and may be difficult to diagnose. It has been described as a rare cause of sudde $\overrightarrow{3}$ heart failure in pregnancy (McKeown, 1948). A 8 interesting condition is that of chorea gravidarure which seems to be identical with Sydenham? chorea, and may be accompanied by active carditis. It is a strange fact that a recent attack of chorea may become reactivated during pregnance (Wilson and Preece, r932; McEilin, Lovelady ang Woltman, 1948).

\section{Congenital Heart Disease}

Congenital abnormalities account for betwe $\frac{\vec{A}}{\mathrm{~A}}$ 5 and $10 \%$ of cases of heart disease in pregnancy. The reported cases are unrepresentative becapis rare and unusual cases with severe symptoms are more often reported than others. On the whe the severe forms of the disease, especially those with cyanosis, either do not survive to the age marriage or do not become pregnant.

Maud Abbott (1920) divided the cases in those (I) with a simple obstruction to the bloof flow in the great vessels, such as pure pulmonary stenosis and coarctation of the aorta, (2) those with an aberrant channel between the heart chambers or great vessels, such as patent ductus arteriosus and septal defects, and (3) combined lesions such as Fallot's tetralogy and Eisenmenger's complex, in which an aberrant channel is combinet with obstruction to the pulmonary outflow.

In the first group the prognosis during prege nancy is usually good. Most of the patients afe without symptoms and have an adequate cardias reserve, and indeed the abnormality may first discovered during pregnancy. Coarctation of the aorta merits a few additional comments, as the diagnosis is often missed, although hypertensio may first be noticed by the obstetrician. During pregnancy there is often no further increase in the hypertension, but the risk of myocardial failure is slightly increase $\Phi_{0}$ Bacterial endocarditis is an ever present danger? but in addition there is the risk of a vascularp accident, either a dissecting aneurysm, or of rupture of some other abnormal vessel. (Benhang 1949; Schnitker and Bayer, 1944; Sundfor, 1950 
Rosenthal (1955) reviewed 96 cases of coarctation, and II of these patients died during pregnancy, but many of these cases were unusual with severe symptoms. Burwell and Metcalf (1958) mention 42 patients who were followed in 63 pregnancies without a death. Most cases do well, and termination of pregnancy would only be justified in cases with myocardial failure or a previous vascular accident. Surgical treatment is possible for both pulmonary stenosis and for aortic coarctation, but in neither case is it an emergency procedure, and any operation would best be done when the patient is not pregnant, and best of all in childhood.

Patients in the second group are usually without disability at the age of pregnancy, in spite of obvious physical signs. Exact diagnosis may require all the resources of cardiac catheterisation and angiography. The flow of blood through the abnormal channel is usually from the left to the right side, and only in a minority of patients and after some time does pulmonary hypertension occur, when secondary obstruction to the pulmonary flow will cause reversal of flow through the shunt, with cyanosis and myocardial failure. This is rarely observed during pregnancy, although during delivery there may be a special risk if hypotension occurs for any reason, such as hæmorrhage or shock, when the fall in the arterial pressure may lead to sudden reversal of flow through the shunt, with cyanosis and collapse. Particularly in cases of patent ductus the risk of bacterial endocarditis is always present. However, on the whole the prognosis during pregnancy is good. Surgical treatment for a patent ductus would not be indicated during pregnancy.

Lutembacher's syndrome (I9I6) of mitral stenosis combined with an auricular septal defect has been described in association with pregnancy on several occasions, and most of the patients have done well.

Cases of the third group are more serious. They are much rarer than the extensive literature suggests. The patients usually have limitation of activity, cyanosis and finger clubbing. The blood flow through the abnormal shunt is from the right to the left side. To the risks of myocardial failure and bacterial endocarditis is added that of collapse at the time of labour because of increased flow through the shunt if the systemic arterial pressure falls for any reason. For these cases termination of pregnancy would sometimes be considered, in spite of several reports of successful pregnancy.

(General references to congenital heart disease: Mendelson and Pardee, I94I; Lund, I948; Kerr and Sodeman, I951; Bramwell and Longson, 1938; Burwell and Metcalf, 1958).

\section{Arrhythmias}

Cardiac arrhythmia has the same significance during pregnancy as in the non-pregnant. Extrasystoles are without sinister significance. Paroxysmal supraventricular tachycardia may occur during pregnancy, and is without danger if the heart is otherwise normal (Szekely and Snaith, I953).

Auricular fibrillation is rare during pregnancy, and such cases as occur are nearly always patients with mitral stenosis, in whom it is a sign of advanced disease and carries a serious prognosis.

Heart block during pregnancy is usually of the congenital type (Mowbray, 1948) and has an excellent progn'ssis; Stokes-Adams attacks are rare.

\section{Bacterial Endocarditis}

During pregnancy bacterial endocarditis is occasionally discovered, usually as a complication of rheumatic valvular disease or of congenital heart disease. In the past, puerperal infections were not infrequently complicated by acute endocarditis (Hamilton and Thomson, I94I), but this is now uncommon. Subacute bacterial endocarditis seems to be more common during pregnancy than in non-pregnant women (Bramwell, I948), and childbirth may be the starting point of the disease (Wauchope, 1929). However, the course of pre-existing endocarditis is not altered by pregnancy, and on the whole the prognosis is good with modern treatment. Because of the special risk in cases of valvular or congenital heart disease the administration of penicillin is advised during labour and for a few days afterwards, and also before and after any dental operation.

Syphilitic aortitis does not usually occur in the childbearing years.

Coronary disease is very rare during pregnancy, because of the ages of the patients. Weinreb, German and Rosenberg, (1957), for example, found that out of 219 women with myocardial infarction only $2.3 \%$ were under 40 years of age.

Hypertensive cardiac disease. Heart failure due to hypertension is rare during pregnancy. Malignant hypertension is itself uncommon and has a short course, so that it is unlikely that pregnancy and the illness will coincide. Essential benign hypertension has seldom progressed to the stage of generalised arteriosclerosis during the reproductive years, or given rise to significant coronary or renal disease.

However, acute pulmonary œdema is sometimes seen in cases of eclampsia, or in severe cases of pre-eclampsia (Szekely and Snaith, 1947; Teel, Reid and Hertig, 1937), and this event is more common than is generally appreciated. 
Puerperal cardiomyopathy. Under this term have been included rare cases of unknown ætiology occurring in late pregnancy or, more commonly, in the first six weeks of the puerperium, characterized by tachycardia, triple ryhthm, cardiac enlargement, and low voltage curves with flat $T$ waves in the ECG. There is no agreement on the pathology, except that no other cause is evident. Recovery is to be expected, but recurrence in successive pregnancies has been described. It is to be hoped that cases will not be thrown into this category without a careful search for a more commonplace ætiology. (Gouley, McMillan and Bellet, I937; Meadows, I957; Melvin, 1947).

\section{Functional Classification of Heart Disease in Pregnancy}

Although the lesions present in a particular case are obviously important, especially in cases of congenital disease, the response of the heart during pregnancy depends more on the state of the myocardium than on that of the valves. Cases may be graded by their functional capacity according to the classification of the New York Heart Association (1955) which may be summarised thus:

Class I. Patients with heart disease but no limitation of activity or symptoms.

Class II. Patients with slight limitation of activity. They are comfortable at rest, but ordinary activity produces symptoms.

Class III. Patients with marked limitation of activity. They are comfortable at rest, but less than ordinary activity causes symptoms.

Class IV. Patients who are unable to undertake any physical activity without discomfort, and who have symptoms even when resting.

The value of this classification is illustrated by Jensen's report (1938), in which the mortality in the respective groups was : Class I, $0.39 \%$, Class II, $0.43 \%$, Class III, $5,3 \%$. Class IV, $22 \%$.

\section{Prognosis}

The management of cardiac disease in pregnancy will be influenced, particularly with regard to termination or sterilisation, by the prognosis. It is not sufficient to consider only the immediate prognosis; the responsibility and work of caring for a child continues for many years, and the number of children and the economic background will obviously affect the domestic load.

\section{The Immediate Prognosis}

In the last twenty years there has been a great reduction in the mortality of heart disease associated with pregnancy and childbirth, and the present overall death rate seems to be about $1 \%$ (Burwell and Metcalf, 1958). At Queen Charlotte's
Maternity Hospital between 1949 and $195^{8}$ t mortality was $0.5 \%$ in 404 cases. Such großs statistics are of little value in assessing the risk for a particular patient, for whom all the circun stances, cardiac, obstetrical and social, need consideration. The following factors are importan

The availability of medical and obstetric care. Many authors have shown that the risk is vefy much greater in patients who do not receive propö supervision or are admitted as emergency cases. (Bramwell and Longson, 1938; Fitzgerald, We 6 ster, Zummo and Williams, I95I).

Age and parity. Cornell and Rosenbau $\vec{\Phi}$ (1959) found that the incidence of failure during pregnancy was $11 \%$ in patients under 25 yea of age, $21 \%$ in those between 26 and 35 years $\bar{g}$ age, and $36 \%$ in those over 35 , and even if patients of comparable parity are considered the effect of advancing age is evident. The effect of parify alone is difficult to estimate because age inevitabdy advances with parity, and also because the obstetric risk is much less in second and thin pregnancies than in the first.

Social factors. Adequate help with the care of children and housework is essential, and wifl affect both the immediate and the long-term prognosis.

The cardiac lesion. Many points have alres been discussed. The nature of the valialiar lesion is of far less importance than the state opipe myocardium at the time, and the function al classification of the cases is more significant th any other. With gross cardiac enlargement auricular fibrillation the risk is high because these complications indicate myocardial damage. $\overrightarrow{\mathrm{sf}}$ there is a history of previous heart failure, or If failure is actually present, the prognosis becomes far worse. Twenty-six of Bramwell and Longson's patients (1938) had heart failure when first see ten of these died during pregnancy or soon afterwards, and four more in the next six years.

Even a relatively slight respiratory infection may prove dangerous in these patients.

\section{The Late Prognosis}

Before trying to assess the effect of pregnan on rheumatic heart disease we must first try to discover the usual course of the disease. Abotf two-thirds of the deaths due to this cause occisr before puberty (Martin, 1941; Wilson and Lubschez, 1948; Bland and Jones, 1951), so thitt the patients who are seen in pregnancy are $>a$ selected group who have survived early attacks afd lived beyond the age of the highest mortality $\bar{Q}_{\mathrm{f}}$ the disease. Only the fitter patients are likely to marry and conceive. Gilchrist and Murray-Lyob (1933) compared the expectation of life after the age of twenty in males, nulliparous women argid 
parous women with rheumatic heart disease and found little difference. Boyer and Nadas (1944) and Gorenberg and Chesley (1953) found no difference in the average age at death in similar groups, and concluded that no acceleration of the natural course of the disease by pregnancy could be demonstrated.

Another aspect of the long-term prognosis is more depressing. Gorenberg and Chesley found that $28 \%$ of patients with rheumatic heart disease who survived pregnancy died within ten years, and even in patients classed in grade $\mathrm{I}, 19 \%$ did not live to see the child's tenth birthday. Miller and Metcalf (1956) published better results, and with the aid of cardiac surgery some of their patients actually improved over the years, but their average follow-up was shorter. Figures from Haig and Gilchrist (1949) suggest that there is an increased risk in successive pregnancies, although they do not consider that the progression of the disease is due to pregnancy:-

TABLE I

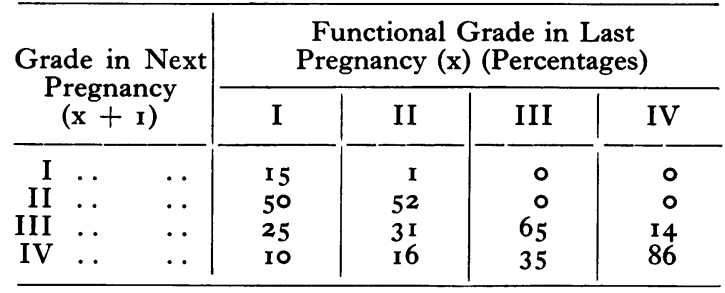

\section{Foetal Mortality}

Estimates of the fœtal mortality in heart disease should include losses due to termination of pregnancy. Burwell and Metcalf (1958) reported a mortality of $18 \%$, half of which was due to interruption of pregnancy. The rate, both for 'spontaneous' and interrupted cases, was higher in the cases with more severe lesions, as Hamilton and Thomson (194I) also found.

The fœtus is often small in cases of heart disease, and spontaneous premature labour may occur in cases with failure (Harris, 1937). No increase in the incidence of fotal abnormalities has been demonstrated, although this possibility has been discussed in cases of maternal congenital disease.

\section{Management \\ The Place of Termination and Sterilisation}

The first question to be decided is whether the pregnancy ought to continue. The problem only arises in a very small number of cases, and the decision is not to be taken hurriedly, nor has the doctor any right to 'forbid' pregnancy. As Burwell and Metcalf (1958) write: 'To many women the completion of pregnancy is part of the definition of a normal and complete life. . . . Factors of morale and morality therefore enter into consideration. Few situations are more destructive of a woman's confidence in the competence of her own heart than the prohibition of pregnancy.... Many patients are held back by religious or moral codes from the acceptance of such advice. . . . A patient whose pregnancy has been interrupted may suffer deep grief and even profound feelings of guilt. ... Such factors are no less real than the obvious medical considerations'.

The actual operation is not without risk. Vaginal termination is certainly not just a curettage; it is a messy procedure attended by free hæmorrhage and the danger of perforation of the uterus. If physicians had to do the operation themselves some of them might recommend it less freely. Hysterotomy carries all the disadvantages of laparotomy, but is safer than vaginal termination after the twelfth week. Some have held that it is always more dangerous to terminate a pregnancy for heart disease than to allow it to continue. Although this view is too extreme, it is certainly highly dangerous to operate on any patient who is in failure at the time, and the aim must always be to obtain the greatest possible improvement before the operation.

There is no absolute indication for termination, and decision is not made on the basis of a formula or rule, but after weighing all the circumstances of the particular case. It is indicated for many patients in grade IV. (Such patients should not become pregnant, as the maternal mortality is at least $10 \%$, and the fotal mortality approaches $50 \%$.) The heart failure must first be treated, but there is often only a partial response to treatment, and the choice of the best time for operation is difficult.

Some of the most worrying cases are those in which progressive and serious deterioration is occurring in spite of treatment, though fortunately they are rare. Even in mid or late pregnancy hysterotomy or Cæsarean section must occasionally be considered, but is obviously a desperate measure with a high risk if failure is present at the time. Termination is not often necessary once the child is viable, and nothing is gained by the induction of premature labour in the last month, when the cardiac output is falling.

The indications for sterilisation are perhaps wider. If termination is really justifiable then further pregnancy will only be advisable in exceptional cases, but sterilisation may also be considered for other patients with less severe disease who have several children or who have obstetric complications. Contraception may be 
an effective alternative, but a physician who advises a patient to avoid pregnancy has a duty, often neglected, of seeing that she knows how to do this. Such advice is not to be given lightly; all too often the obstetrician meets a frightened woman who has been told, with little reason, that pregnancy would be dangerous for her.

\section{Cardiac Surgery}

Valvotomy for mitral stenosis may enable a few patients to undertake pregnancy with greater safety afterwards, but the place of surgery during pregnancy, possibly as an alternative to termination, also needs discussion. The operation is certainly possible during early or mid-pregnancy and many reports have appeared (Brock, 1952; Burwell and Ramsey, 1953; Mendelson, 1955; Glover, McDowell, O'Neill and Janton, 1955), but do such operations in fact alter the risk during pregnancy? The maternal mortality is low in pregnancy except for cases in groups III and IV, and it must not be forgotten that the mortality of valvotomy is about $5 \%$. The operation is not necessary for cases with little disability, and it is unsuitable for cases in which mitral stenosis is not the dominant lesion, or for cases with chronic congestive failure and considerable cardiac enlargement. In general the results will be better if the operation is performed when the patient is not pregnant, for then the cardiac load is less, assessment is easier, and the benefit of the operation preceeds pregnancy. At times, however, acute pulmonary odema is critical and the operation cannot be postponed.

\section{Antenatal Care}

In most of the patients pregnancy will proceed without the need to consider either termination or cardiac surgery. These patients need closer supervision than other antenatal patients, and ideally they should be seen at each visit by both the physician and the obstetrician, but unless there is a combined clinic some thought must be given to these arrangements to avoid too many attendances by the patient, with the corresponding fatigue and risk of respiratory infection from other patients. The danger of such infections must be explained to the patient so that she can report any illness, and penicillin may be given for prophylaxis or admission if necessary. Penicillin should also be given before or after any dental operation.

Adequate rest is the most important single factor in reducing the cardiac load, and definite instructions to have at least ten hours in bed each night and two hours rest each afternoon should be given. Home arrangements need consideration, and the provision of help with shopping and housework may be invaluable. Patients benefit greatly from a rest in hospital from the thirts second to the thirty-sixth week, when the cardias output is highest, and patients with any sign of deterioration or decompensation would be admitted at any time.

If heart failure supervenes all the usual medicat treatment is given, including when indicatedf digitalis, quinidine and diuretics. In cardias failure there is a generalised vaso-constriction and at the same time there is a retention of sodiun and water by the kidney. The part played bo aldosterone in this is still under investigations (See discussion by Gorlin, 1961). The increase i $\bar{B}$ the blood volume and total body water in pregnancy is well-known, and some authorities believe that restriction of the intake of sodium will limit the increase in plasma volume and diminish the cardiac burden, although why this should happen is far from clear. It is possible thæe increase in the blood volume is especially significt cant if it contributes to increase in the pulmonary intravascular pressure. It is not necessary of practical to alter the diet of mild cases.

Management of labour. Fortunately most patients with heart disease proceed uneventfully to term, although a few will start labour pre maturely. Vaginal delivery is always safer than Cæsarean section unless there is some obstegrif complication. It is utterly wrong to recommend Cæsarean section because it provides an op tunity to sterilise the patient; that operation more safely performed early in the puerperium after vaginal delivery.

In the first stage of labour sedatives such $\frac{\mathbb{D}}{2 \mathrm{~s}}$ pethidine and promazine are used freely to ensur $\vec{\delta}$ that the patient rests between contractions, and throughout labour the patient may be in a seme recumbent position. Unless a rapid delivery obviously in progress the muscular effort of the second stage can be reduced by episiotomy an $\overrightarrow{\text { d. }}$. assisted delivery with forceps. A pudendal block carries less risk than a general anæsthetic, but that is necessary the services of a skilled anæsthetis should be sought. Particular care must be taken to avoid anoxia.

It is often said that patients with heart disease have short labours, but this was not confirmed b Nelson and Eades (1935).

Postpartum care. It is also said that acute pulmonary œdema may occur in the third stage of labour because a large volume of blood frore the uterine sinuses is suddenly expelled into the circulation. In fact sudden cardiac failure is mofe common in the puerperium than in the thirg stage of labour, and Hamilton and Thomson (I94I) state that $75 \%$ of the deaths of theip cardiac patients occurred during the puerperium No case that has been decompensated is out of 
danger in the puerperium until all signs of pulmonary congestion have passed.

Most patients with heart disease should have at least three weeks rest after delivery, and some will need much longer periods in hospital. Puerperal infection is a danger to these patients, and the risk of bacterial endocarditis has already been discussed. Thrombophlebitis seems to be more common in these patients than in others, perhaps because of inadequate attention to leg movements in patients who are confined to bed.

Lactation may be permitted if the patient has no functional disability, but is inadvisable in the severe cases.

Finally, the physician should discuss the future care of the patient. If another pregnancy seems inadvisable then sterilisation or contraception may need to be arranged, but if another pregnancy is intended then an interval of two years between the children's birthdays may relieve the domestic load. Most of these patients are co-operative and anxious to maintain their health for the sake of their children, and their gratitude makes their care rewarding.

\section{REFERENCES}

Aввотт, M. E. (1936): ' Atlas of Congenital Cardiac Diseases'. New York: Amer. Heart Assoc.

Adams, J. Q. (1954): Cardiovascular Physiology in Normal Pregnancy, Amer. F. Obstet. Gynec., 67, 741.

Asali, N. S., Douglas, R. A., jr., Baird, W. W., Nicholson, D. B., and SuYemoto, R. (I953): Measurements of Uterine Blood Flow and Uterine Metabolism, Ibid., 66, 248.

Barcroft, J., Herkel, W., and Hill, S. (I933): The Rate of Blood Flow and Gaseous Metabolism of the Uterus During Pregnancy, F. Physiol., 77, 194.

Benham, J. H. H. (1949): Pregnancy and Coarctation of the Aorta, F. Obstet. Gyncec. Brit. Emp., 56, 606.

BLAND, E. F., and JoNES, T. D. (195I): Rheumatic Fever and Rheumatic Heart Disease, Circulation, $4,8_{3} 6$.

Boyer, N. H., and NADAS, A. S. (1944): The Ultimate Effect of Pregnancy on Rheumatic Heart Disease, Ann. intern. Med., 20, 99.

Bramwell, C. (1948): Subacute Bacterial Endocarditis, Lancet, ii, 48I.

, and Longson, E. A. (1938): 'Heart Disease and Pregnancy'. London: Oxford University Press.

Brehm, H., and Kindling, E. (1955): Der Kreislauf wahrend Schwangerschaft und Wochenblatt, Arch. Gynäk., $185,696$.

BRock, R. C. (1952): Valvulotomy in Pregnancy, Proc. roy. Soc. Med., 45, 538.

Bucht, H. (195I): Studies on Renal Function in Man with Special Reference to Glomerular Filtration and Renal Plasma Flow in Pregnancy, Scand. F. clin. Lab. Invest., 3, Suppl. 3.

Burwell, C. S., and Metcalf, J. (1958): 'Heart Disease and Pregnancy'. London: J. \& A. Churchill. , and Ramsey, L. H. (1953): Surgery of the Mitral Valve and the Management of Mitral Stenosis in Pregnant Women, Trans. Ass. Amer. Phycns., 66, 303.

, Strayhorn, W. D., Flickinger, D., Corlette, M. B., Bowerman, E. P., and Kennedy, J. A. (i938): Circulation During Pregnancy, Arch. intern. Med., 62, 979.

Correll, H. L., and Rosenbaum, F. F. (1950): Multiple Pregnancies in Patients with Rheumatic or Congenital Heart Disease, Amer. Heart Y., 39, 283.

Cugell, D. W., Frank, N. R., Gaensler, E. A., and Badger, T. L. (1953): Pulmonary Function in Pregnancy, Amer. Rev. Tuberc., 67, 568.

Fitzgerald, J. E., Webster, A., Zummo, B. P., and Williams, P. C. (I95I): Evaluation of Adequate Antepartum Care for the Cardiac Patient, f. Amer. med. Ass., 146, 9 I0.

Gilchrist, A. R., and MURRAY-Lyon, R. M. (1933): Edinb. med. F., 40, 587.

Glover, R. P., McDowell, D. E., O'NeIll, T. J. E., and JANTon, O. H. (1955): Mitral Commisurectomy in Relation to Pregnancy, F. Amer. med. Ass., 158, 895 .

Gorenserg, H., and Chesley, L. C. (1953): Rheumatic Heart Disease in Pregnancy; Immediate and Remote Prognosis, Obstet. and Gynec., I, 15.

GorLIN, R. (196r): Regulation of Intravenous Volume in Chronic Congestive Failure, Brit. med. F., i, I1 28.

Gouley, B. A., McMillan, T. M., and BeLlet, S. (1937): Idiopathic Myocardial Degeneration.Associated with Pregnancy and the Puerperium, Amer. F. med. Sci., 194, 185.

Haig, D. C., and Gilchrist, A. R. (I949): Heart Disease Complicated by Pregnancy, Trans. Edinb. med. Soc., p. 55.

Hamilton, B. E., and Thomson, K. J. (I94I): 'The Heart in Pregnancy and the Childbearing Age'. Boston: Little, Brown.

Hamilton, H. F. H. (1949): Cardiac Output in Normal Pregnancy, F. Obstet. Gynac. Brit. Emp., 56, 548.

HARRIS, K. (I 937): Heart Disease with Normal Rhythm Complicating Pregnancy, Lancet, i, 677.

Hendricks, C. H., and Quilligan, E. J. (1956): Cardiac Output During Labour, Amer. F. Obstet. Gynec., 71, 953.

Hollander, A. G., and CRAWFord, J. H. (I943): Roentgenologic and Electrocardiographic Changes in the Normal Heart During Pregnancy, Amer. Heart $\mathcal{F}_{\text {, }}, 26,364$.

Jensen, J. (1938): 'The Heart in Pregnancy'. London: Henry Kimpton.

Kerr, A., Jr., and Sodeman, W. A. (1951): Congenital Heart Disease in Pregnancy, Amer. Heart Y., 42, 436.

Lund, C. J. (1948): Maternal Congenital Heart Disease as an Obstetric Problem, Amer. F. Obstet. Gynec., 55, 244.

Lutembacher, R. (i916): De la stenosé mitral avec communication interauriculaire, Arch. Mal. coeur, 9, 237.

MACKenZIE, J. (1921): 'Heart Disease and Pregnancy'. London: H. Frowde and Hodder and Stoughton.

McCaLL, M. L. (1949): Cerebral Blood Flow and Metabolism in Toxæmia of Pregnancy, Surg. Gynec. Obstet., 89, 715.

McEilin, T. W., Lovelady, S. B., and Woltman, H. W. (1948): Chorea Gravidarum, Amer. F. Obstet. Gynec., 55, 992.

McKeown, F. (1948): Acute Rheumatism in Pregnancy, F. Obstet. Gynac. Brit. Emp., 55, 50.

Marshall, R. (1949): 'Heart Disease and Pregnancy'. Paper read before British Cardiac Society. 
Martin, A. T. (194I): Twenty Years' Observation of 1,438 Children with Rheumatic Heart Disease, F. Amer. mede Ass., 117, 1663.

Meadows, W. R. (1957): Idiopathic Myocardial Failure in the Last Trimester of Pregnancy, Circulation, I5, 903.

Melvin, J. P. (1947): Postpartal Heart Disease, Ann. intern. Med., 27, 596.

Mendelson, C. L. (1955): Supportive Care, Interruption of Pregnancy, and Mitral Valvulotomy in the Management of Mitral Stenosis Complicating Pregnancy, Amer. F. Obstet. Gynec., 69, 1233.

-, and Pardee, H. E. B. (194I): Congenital Heart Disease During Pregnancy, Amer. F. med. Sci., $202,392$.

MetCalf, J., Romney, S. L., Ramsey, L. H., Reid, D. E., and BuRwell, C. S. (1955): An Approach to the Measure ment of Uterine Blood Flow in Pregnancy, $\mathcal{F}$. clin. Invest., 34, 1632.

Miller, M. M., and Metcalf, J. (1956): Effect of Pregnancy on the Course of Heart Disease, Circulation, 13, 481.

Mowbray, R. (1948): Heart Block and Pregnancy, F. Obstet. Gynac. Brit. Emp., 55, 432.

Munnell, E. W., and TAYlor, H. C., Jr. (I947): Liver Blood Flow in Pregnancy. F. clin. Invest., $26,952$.

Nelson, H. B., and EAdes, F. S. (r935): Some Aspects of Cardiac Disease Complicated by Pregnancy, New Engl. $\mathfrak{O}_{0}$ Med., 213, 1057.

Newton, W. H. (1939): ' Recent Advances in Physiology'. London: J. \& A. Churchill.

New York Heart Association (1955): "Nomenclature and Criteria for Diagnosis of Diseases of the Heart and Blood Vessels. Oram, S. (I95I): 'Medical Disorders in Pregnancy'. Editors: S. G. Clayton and S. Oram. London: J. \&. A $\vec{\sigma}$
Churchill.

Plass, E. D., and OBerst, F. W. (1938): Respiration and Pulmonary Ventilation in Normal Non-pregnant, Pregnar@ and Puerperal Women, Amer. F. Obstet. Gynec., 35, 44I.

'Queen Charlotte's Textbook of Obstetrics' (196r). London: J. \& A. Churchill.

Rosenthal, L. (1955): Coarctation of the Aorta, Brit. med. F., i, 16.

Schnitker, M. A., and BAYER, C. A. (1944): Dissecting Aneurysm of the Aorta in Young Individuals, Particularly inct Relation to Pregnancy, Ann. intern. Med., 20, 486.

SundFor, H. (I 950): Coarctatio aortæ og svangerskap, Nord. méd., 43, 953.

Szekely, P., and Snaith, L. (1947): The Heart in Toxæmia of Pregnancy, Brit. Heart f., 9, 128.

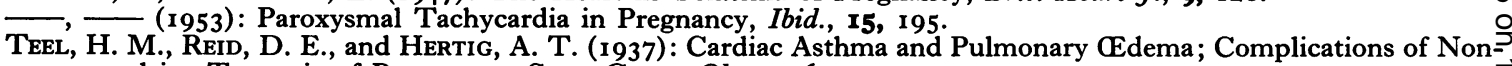
convulsive Toxæmia of Pregnancy, Surg. Gynec. Obstet., 64, 39.

Ungerleider, H. E., and Clark, C. P. (1939): A Study of the Transverse Diameter of the Heart Silhouette, witlo Prediction Table Based on Teleroentgenograms, Amer. Heart F., 17, 92.

WAUChOPE, G. M. (1929): Endocarditis Lenta, Lancet, i, 859.

Weinreb, H. L., German, E., and Rosenberg, B. (1957): A Study of Myocardial Infarction in Women, Ann. intêfn Med., 46, 285 .

Werkö, L. (I950): ' Studies in the Problems of Circulation in Pregnancy' in Ciba Foundation Symposium 'Toxæmie of Pregnancy', edited by J. Hammond, F. J. McC. Browne and G. E. W. Wolstenholme, p. I55. Lond年电 Churchill.

- (1954): Pregnancy and Heart Disease, Acta obstet. gynec. scand., 33, r62.

Widlund, G. (1945): Cardio-pulmonal Function in Pregnancy, Ibid., 25, Suppl. I.

Wilson, M. G., and LubSChez, R. (1948): Longevity in Rheumatic Fever, f. Amer. med. Ass., 138, 794.

Wilson, P., and Preece, A. A. (1932): Chorea Gravidarum, Arch. intern. Med., 49, 471.

Woodbury, R. A., Hamilton, W. F., and ToRPIN, R. (1938): The Relation Between Abdominal, Uterine and Arteria $\overrightarrow{5}$ Pressure During Labour, Amer. F. Physiol., 121, 640. 